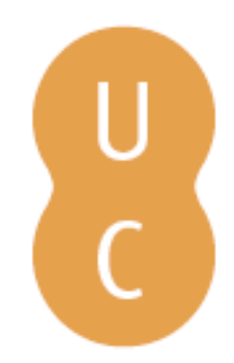

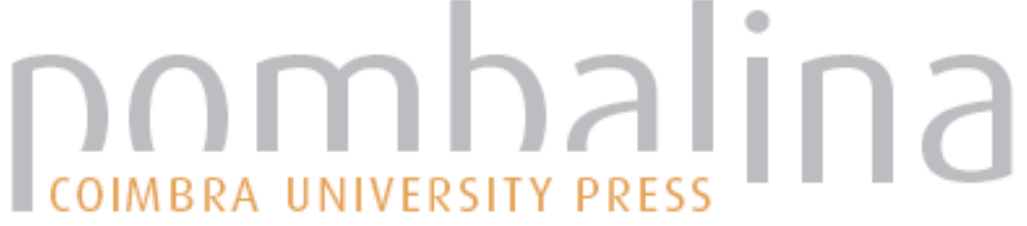

\section{Educação história e história da educação}

Autor(es): Barca, Isabel

Publicado por: Imprensa da Universidade de Coimbra

URL

persistente: URI:http://hdl.handle.net/10316.2/38582

DOI: $\quad$ DOI:http://dx.doi.org/10.14195/978-989-26-0646-0_11

Accessed : $\quad$ 26-Apr-2023 13:55:20

A navegação consulta e descarregamento dos títulos inseridos nas Bibliotecas Digitais UC Digitalis, UC Pombalina e UC Impactum, pressupõem a aceitação plena e sem reservas dos Termos e Condições de Uso destas Bibliotecas Digitais, disponíveis em https://digitalis.uc.pt/pt-pt/termos.

Conforme exposto nos referidos Termos e Condições de Uso, o descarregamento de títulos de acesso restrito requer uma licença válida de autorização devendo o utilizador aceder ao(s) documento(s) a partir de um endereço de IP da instituição detentora da supramencionada licença.

Ao utilizador é apenas permitido o descarregamento para uso pessoal, pelo que o emprego do(s) título(s) descarregado(s) para outro fim, designadamente comercial, carece de autorização do respetivo autor ou editor da obra.

Na medida em que todas as obras da UC Digitalis se encontram protegidas pelo Código do Direito de Autor e Direitos Conexos e demais legislação aplicável, toda a cópia, parcial ou total, deste documento, nos casos em que é legalmente admitida, deverá conter ou fazer-se acompanhar por este aviso.

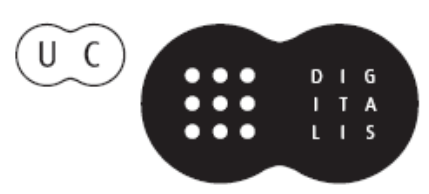




\section{EDUCAÇÃo HISTÓRICA E HISTÓRIA \\ DA EDUCAÇÃ̃o}

ISABEL BARCA

CIED, UNIVERSIDADE DO MINHO

Em países de língua portuguesa é frequente encontrar-se uma confusão conceptual entre duas áreas de pesquisa educacional que por vezes se cruzam, mas são diferentes entre si: a Educação Histórica e a História da Educação. Tendo embora estas áreas algumas possibilidades ocasionais de enfoque convergente - por exemplo, sobre a discussão de modelos de Ensino da História no passado - no seu âmago elas têm objetos, metodologias e finalidades distintas. Se a História da Educação investiga diversas problemáticas educacionais em diversos tempos e lugares, segundo metodologias essencialmente historiográficas e com a finalidade de contribuir para a compreensão da Educação numa perspectiva diacrónica, a pesquisa em Educação Histórica focaliza-se no ensino e aprendizagem da História em contextos atuais, utiliza metodologias que abrangem diversos procedimentos empíricos das Ciências da Educação (que assentam nos das Ciências Sociais) e tem por finalidade contribuir - e intervir - diretamente para uma inovação refletida das práticas de ensino e aprendizagem da História.

\section{Investigação em Educação histórica}

$\mathrm{Na}$ abordagem de Educação Histórica, centrada portanto em situações de ensino e aprendizagem atuais, a pesquisa encontra-se na interface de 
vários saberes: a Teoria Curricular, a História, a Epistemologia da História, a Metodologia das Ciências Sociais, a Psicologia da Aprendizagem. Procura-se entender como é que os sujeitos - sobretudo os alunos - constroem o conhecimento em História, e que caminhos poderão ser mais frutuosos para aprofundar a qualidade dessa construção. Por tudo isto, a área de investigação em Educação Histórica reivindica um estatuto científico específico que tem como objeto principal as concepções históricas dos vários tipos de sujeitos que, no diálogo mental entre as suas ideias de senso comum e uma conceptualização mais sistematizada pelo contacto com a ciência histórica, vão evoluindo (ou não) no seu pensamento histórico. Estes princípios convergem com vários estudos educacionais em diversas disciplinas, de teor construtivista, que é considerado um paradigma que melhor responde às questões e necessidades de formação dos seres humanos na sociedade atual (ARENDS, 1997; FOSNOT, 1999). De realçar que o paradigma construtivista em Educação, embora tenha evoluído a partir de princípios que defendem metodologias de trabalho dos alunos (como as pedagogias de Freinet e de Paulo Freire), se distancia de modelos de aula ativa que não se orientem para a qualidade conceptual alojada na ciência de referência. Também se distancia do modelo exclusivamente transmissivo, que até pode ser altamente motivador:

Não há talvez ciência mais própria para entusiasmar os jovens do que a história, mas a história animada, plástica, cheia de personagens vivas, que pensem, falem, gesticulem, obrem, se agitem, perante os olbos fascinados do neófito, em uma corrente viva e rápida, consoante com o pulsar juvenil do seu coração. Cecília Schmidt Branco, 1891 (in TORGAL, 1996, p. 470)

Este excerto da pedagoga Cecília Schmidt remete-nos para a possibilidade da exposição docente - que deve existir mas não deve constituir-se como modelo hegemónico ao longo processo de ensino e aprendizagem - eventualmente se confundir com uma aula ativa por excelência só porque se mostra cativante para os alunos. Ao analisarmos o texto, compreendemos que a autora defende que uma temática histórica vibrantemente exposta pelo/a professor(a) causará certamente adesão e entusiasmo nos jovens que assistem a esta exposição, com "olhos fascinados". E claro, também hoje se considera fundamental a aposta em 
ganhar os jovens para a relevância de entender o pulsar da História, tão próximo das suas e nossas vidas. Contudo, se queremos desenvolver nos jovens a construção de ideias históricas, a exposição docente por mais arrebatada que seja é uma condição necessária mas não suficiente para que os jovens, além de gostarem de História, também a compreendam e relacionem de forma válida com as suas vidas. Permito-me relembrar aqui algumas memórias pessoais de quando era professora de História no ensino não superior:

Defensora da escola ativa e da pedagogia do trabalbo (ainda não se falava de construtivismo), tinha como princípio remeter para trabalbos de grupo o início da compreensão das estruturas históricas, por meio de tarefas de análise e interpretação de fontes sobre a História local e global, a partir das quais se construíam inferências de síntese; reservava a minha exposição sobretudo para os episódios narrativos com "personagens vivas, que pensem, falem, gesticulem, obrem, se agitem", como propunha Cecília Schmidt no século XIX. Era um feliz alvoroço na sala: os alunos participavam, apoiavam ou recusavam as ações das suas personagens favoritas ou malditas. Contudo... Nos testes de avaliação sumativa não era visível uma compreensão histórica que acompanhasse esse entusiasmo geral. E um dia fiz a experiência: no final da minha exposição, propus aos alunos que narrassem, por palavras suas, a situação bistórica que eu lhes contei e a que pareciam aderir tão vivamente. Percebi então que, de facto, se uma parte dos alunos se apropriava de alguns elementos significativos da trama, na esmagadora maioria as suas narrativas detinham-se em detalhes avulsos ou então as personagens e ações ganhavam contornos perigosamente ficcionais. Foram experiências como esta que me levaram a procurar respostas sistemáticas às minhas perplexidades e embrenhar-me na investigação educacional focalizada na compreensão das ideias dos agentes educativos em concreto.

Na investigação em cognição histórica - que dá resposta a essas perplexidades - a agenda investigativa inverte a pirâmide normal das preocupações em Educação: dá-se mais destaque à busca de compreensão das ideias históricas de alunos e de professores, em aula ou fora dela, deixando para segundo plano (mas não rejeitando) os estudos sobre manuais, currículos e outros documentos de política educativa (Figura 1). 


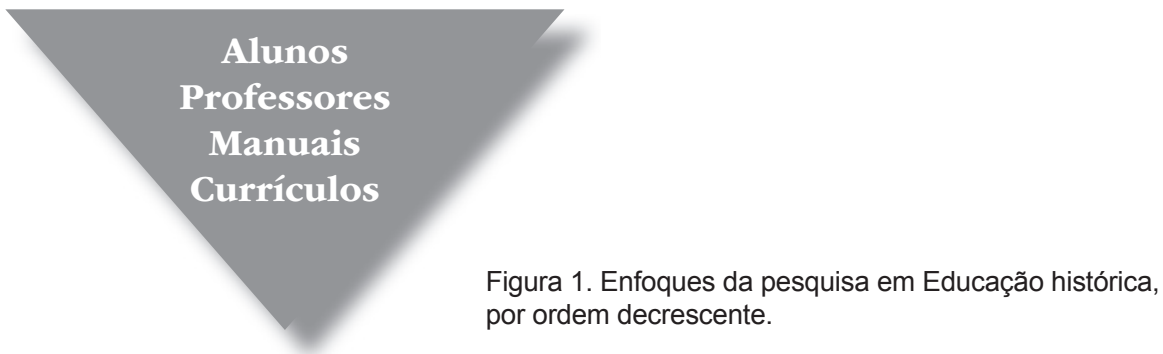

Esta linha de pesquisa, que nasce em Inglaterra na década de 1970, parte do princípio de que é possível a construção de ideias históricas gradualmente mais sofisticadas pelas crianças e jovens no que respeita a natureza do conhecimento histórico, se o Ensino for orientado nesse sentido. Este pressuposto tem sido confirmado em vários estudos essencialmente qualitativos, em que a análise dos dados empíricos é feita em profundidade (ASHBY, LEE \& SHEMILT, 2005; BARCA, 2007a; COOPER \& CHAPMAN, 2009; SCHMIDT, 2009). Confere uma especial atenção às concepções meta-históricas a partir da leitura que o investigador faz das ideias substantivas. A essa conceptualização meta-histórica costuma também chamar-se "ideias de segunda ordem", na expressão proposta por Peter Lee em vários dos seus trabalhos, para sinalizar noções que estão imersas na compreensão da história substantiva e que tecem a natureza deste saber específico. Assim, para além de conteúdos e respectivos conceitos particulares acerca de determinado passado em estudo - por exemplo, a Independência do Brasil ou de Portugal - na análise desses saberes procura-se perscrutar que tipo de conhecimento histórico os sujeitos vão construindo. Indaga-se, então, particularmente no âmbito da cognição histórica dos alunos:

- Qual a natureza da compreensão histórica que os sujeitos manifestam - uma simples descrição sem relações entre tempos, uma listagem pré-estabelecida e desconexa de "causas" e ou "consequências", uma narrativa explicativa fechada, ou uma outra mais pessoal, problematizada mas historicamente válida?

- Que usos fazem das várias fontes disponíveis para o estudo de um certo passado: simples transcrição, soma de informações convergentes, ou cruzamento inferencial e contextualizado de mensagens diversificadas?

- Até que ponto são considerados e "pesados" argumentos discordantes? 
- Que sentidos de mudança estão inerentes às suas próprias produções (mais ou menos) históricas: progresso, retrocesso, ciclo, dialética?

- Que relevância ('significância') para a atualidade atribuem à História?

À preocupação de compreender como as crianças e jovens constroem as suas ideias em torno dos conceitos que dão consistência ao saber histórico, juntou-se na década de 1990 a de se explorar a consciência histórica dos jovens, uma ideia que se fundamenta em reflexões filosóficas de Jörn Rüsen (RÜSEN, 1993, 2001; SCHMIDT, BARCA \& MARTINS, 2010). O debate filosófico de Rüsen assenta no pressuposto de que há uma necessidade de orientação temporal intrínseca nos seres humanos que se alimenta das relações conceptuais entre perspectivas de passado, presente e futuro que cada sujeito constrói. Aprofundando a compreensão em torno das inter-relações de diversos segmentos temporais com base na interpretação das fontes à maneira do historiador (uso da evidência histórica, um conceito contra-intuitivo longe de ser óbvio), os seres humanos percebem-se como parte de um contexto humano muito maior do que as suas próprias vidas e adquirem ferramentas conceptuais para (melhor?) se orientarem e se constituírem como agentes do seu próprio tempo.

Na discussão aprofundada do conceito de consciência histórica, Rüsen (1993) cartografa numa matriz conceptual a sua leitura das relações entre o saber histórico e a vida prática (lebenpraxis): a História com as suas teorias, métodos e formas alimenta-se dos interesses e funções da vida prática, sendo desejável que esta seja, por sua vez, por ela alimentada de forma consistente (Figura 2).

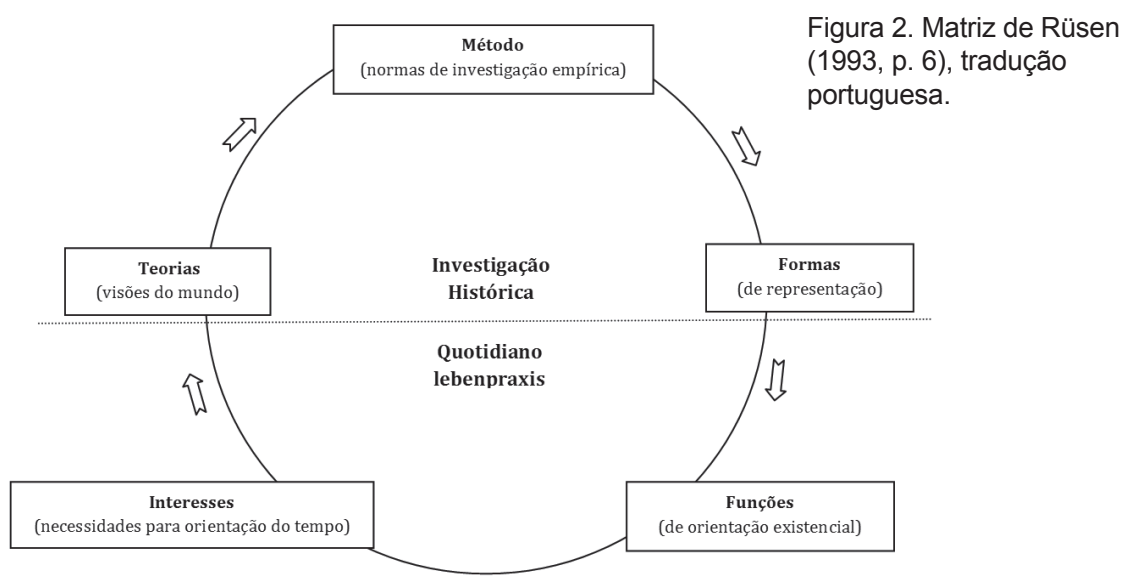


A consciência histórica será algo que ocorre quando a informação inerte e progressivamente interiorizada se torna parte da ferramenta mental do sujeito e é utilizada, com alguma consistência, como orientação no quotidiano pessoal e social. Neste contexto, a narrativa (não necessariamente apenas textual) é entendida como a face da consciência histórica, enquanto forma usual de produção dentro de qualquer escola historiográfica. Tal não significa que tudo vale como narrativa histórica. Numa postura que reconhece a validação intersubjetiva no seio da comunidade científica (MARTIN, 1998; FULBROOK, 2002), existem critérios metodológicos que tornam possível a discussão e a avaliação relativa das produções historiográficas.

\section{Educação histórica: investigação em Portugal e no Brasil}

Em consonância com a investigação mais frutuosa em educação histórica que encontra a sua primeira fonte de inspiração nas pesquisas de Denis Shemilt, Martin Booth, Peter Lee e Alaric Dickinson no Reino Unido, em Portugal e no Brasil a pesquisa tem-se centrado na exploração analítica das ideias substantivas e de segunda ordem, especialmente dos alunos:

- Evidência ou interpretação cruzada de fontes diversificadas, incluindo as que contêm divergência (CARVALHO, 2010; FRONZA, 2011; PINTO, 2007; SIMÃO, 2007);

- Explicação intencional e multiperspectivada (BARCA, 2000; DIAS, 2007; FERNANDES, 2009);

- Narrativa e consciência histórica (BARCA, 2007a; CARDOSO, 2011; COMPAGNONI et al., 2006; GAGO, 2011; GEVAERD, 2011; SCHMIDT, 2008).

Discutir-se-ão aqui alguns resultados desses estudos, realizados no âmbito dos Projetos HICON (Consciência Histórica - Teoria e Práticas) ${ }^{1}$ sobre narrativas de jovens colhidas em escolas de países lusófonos, nomeadamente em

\footnotetext{
1 Projetos Hicon I, 2003-2007, e Hicon II, 2007-2011, financiados pela Fundação para a Ciência e Tecnologia, Portugal.
} 
Portugal e no Brasil ${ }^{2}$ (BARCA, 2011; COMPAGNONI et al., 2006; RIBEIRO, 2011; SADDI \& SILVA, 2011; SCHMIDT, 2008).

\section{Método investigativo}

Os estudos aqui relatados, que se centraram na exploração de "narrativas históricas" numa abordagem qualitativa, tiveram como sujeitos participantes jovens portugueses e brasileiros em final de escolaridade básica (idades entre 14 e 17 anos). Com o objetivo de se garantir alguma heterogeneidade da amostra participante, realizou-se uma amostragem estratificada por regiões em cada país, selecionando-se duas turmas de escolas por cada região, de acordo com a disponibilidade das escolas. Em recolhas de dados entre 2005 e 2011, as turmas participantes pertenciam a escolas na periferia de cidades localizadas em áreas diversas: a) no Brasil, duas turmas em Curitiba, duas turmas em Goiânia e duas turmas em São Paulo; em Portugal, duas turmas em Braga, duas turmas em Faro, duas turmas em Lisboa e duas turmas no Porto.

Relativamente aos instrumentos e sua aplicação em ambiente de aula de História, e com a colaboração de professor(a) a quem os investigadores entregaram instruções procedimentais, propôs-se aos alunos a realização de duas tarefas individuais, escritas: imaginando que se encontravam num encontro de jovens de todo o mundo pedia-se, em primeiro lugar, "Conta a História do teu país nos últimos cem anos" e, após recolha da tarefa, pedia-se “...Conta a História do Mundo nos últimos cem anos". Aos alunos estrangeiros era dada oportunidade de narrarem a história nacional do país de origem ou de acolhimento $^{3}$. Cada tarefa teve uma duração de cerca de 30 minutos.

\section{Narrativas de jovens portugueses e brasileiros}

A análise indutiva das produções dos jovens orientou-se pela prospeção de ideias em torno de núcleos conceptuais: estrutura narrativa, marcadores substantivos, marcos cronológicos, consciência histórica. Apresentam-se e

\footnotetext{
2 Nos projetos referidos, investigaram-se também narrativas de jovens de Cabo Verde e Moçambique, não discutidos neste artigo.

3 Foram muito raros os casos em que os alunos optaram por contar a História do seu país, pelo que aqui não serão discutidos.
} 
discutem-se, neste artigo, alguns dos resultados em torno do núcleo conceptual "consciência histórica". Dentro deste núcleo, exploraram-se os sentidos das mensagens dos alunos relativos a:

- Identidade e consciência histórica

- Mudança

- O sujeito na História

\section{Identidade e consciência histórica}

Nas produções dos jovens portugueses, um dos resultados mais nítidos, que se manifestou com acentuada regularidade ao longo das várias etapas de recolha, foi o de as histórias nacionais se mostrarem mais estruturadas e substanciadas do que as histórias mundiais. Com efeito, embora algumas produções sobre o país aparecessem como simples listas (a)cronológicas ou como narrativas genéricas ou fragmentadas, muitas delas podem considerar-se como narrativas históricas descritivo-explicativas, parte delas de caráter "emergente" (quando narram com consistência uma "fatia" significativa do período em causa), outras "completas" (no sentido de procurar dar conta, de forma autónoma, de um fio da história ao longo dos últimos cem anos). Destas últimas é exemplo a do Jorge, de 16 anos, a frequentar uma escola do Porto, em 20114:

Bem há cerca de 100 anos começou a república, com a queda da monarquia. Salazar governou o país numa ditadura que inspirou medo a todo o país. Torturava pessoas, e viviam num país não livre. Governou-o durante vários anos. Salazar teve um acidente e ficou incapacitado de governar o país, passando esse 'poder' a Marcelo Caetano, que governou segundo as bases de Salazar, mas tentou 'suavizar' um pouco as coisas. Portugal, farto da ditadura, organizou uma Revolução dos Cravos ou 25 de Abril. Ao longo dos anos, o país foi enfrentando vários problemas. Em 2001, foi criada a moeda atual da União Europeia, o Euro. Agora, em 2011, estamos a enfrentar uma enorme crise económica, que se alastra por Portugal.

${ }^{4}$ Os nomes dos alunos aqui apresentados são fictícios e as suas produções apenas foram alteradas no que respeita a alguma ortografia e pontuação. 
Já sobre a História mundial, entre os jovens portugueses não aparecem narrativas a que possamos chamar completas. As produções apresentam-se frequentemente como comentários genéricos ou listagens; no máximo, surgem narrativas emergentes como a de José, de 15 anos, que giram sobretudo em torno das duas guerras mundiais, saltando quase de seguida para acontecimentos da atualidade:

Em 1914 ocorreu a $1^{a}$ Guerra Mundial que perdurou até 1918. Essa guerra trouxe imensas consequências para todos os países que nela intervieram, nomeadamente sociais, económicas e políticas. Na década de 30, em alguns países surgiram regimes extremistas, como em Itália, Alemanha, Espanha e Portugal, liderados respectivamente por Mussolini, Hitler, Franco e Salazar. No outro extremo da Europa (Rússia) apareceu um regime comunista, primeiro governado por Lenine e depois por Estaline. Entre 1939 e 1945 deu-se a $2^{a}$ Guerra Mundial. Após isto deu-se um processo de reconstrução dos países da Europa.

Nos últimos anos tem-se vivido um clima de terrorismo causado pelo atentado feito pela Al-Qaeda em 2001 às torres gémeas em Nova York. Assim, temse assistido a guerras em que os EUA aparecem envolvidos, mais especificamente no Afeganistão e no Iraque.

A maior qualidade das narrativas nacionais em termos de estrutura e substância parece indiciar uma identidade nacional mais forte e até mais positiva do que a identidade global. A mensagem nuclear mais recente que tacitamente emerge de forma transversal a quase todas as produções é a de que, em Portugal, o povo conquistou a liberdade sobre a ditadura mas agora encontra-se mergulhado numa profunda crise económica; no mundo, permanecem as guerras e catástrofes ambientais e naturais (embora vários alunos apontem também avanços tecnológicos e científicos). Poder-se-á então dizer que a consciência histórica destes alunos portugueses é usada como fator que tende a fortalecer a identidade nacional, sem que isso signifique uma visão exclusivista da História: os jovens saúdam a liberdade contra a opressão, uma liberdade que se construiu em luta contra inimigos internos e que aceita a cooperação com outros povos. Já o vasto mundo aparece sobretudo como um lugar de perigos vários, um pouco distanciado deste lugar português. 
As primeiras produções de jovens brasileiros, que seguiram a mesma proposta de duas tarefas sobre o país e o mundo contemporâneo (COMPAGNONI ET AL., 2006; SCHMIDT, 2008), apresentam sempre alguma trama narrativa não aparecem simples listagens cronológicas. As narrativas mais consistentes têm uma estrutura de tipo comparativo entre o passado e o presente, com alusão a situações e eventos históricos nesses dois grandes segmentos temporais (passado/presente), sem marcos cronológicos precisos. Estas narrativas de tempo binário tendem a acentuar uma comparação por "temáticas" (conquista de direitos, melhoria de condições de vida...):

Antes as mulheres não tinham o direito de votar, não podia fazer tudo o que queria, não tinha um bom salário, era o pai quem escolbia com quem a filha ia casar, falta de empregos... Hoje em dia as pessoas já têm um emprego melhor, as mulheres já tem direito de voto, todas as pessoas quando completam 16 anos já podem votar, a mulher já pode escolber seu próprio marido, o salário já é melhor, tem mais empregos, etc.

Antes também havia muitas pessoas racistas os negros eram chicoteados, comiam somente pão e água, não ganhavam salários, não tinham direitos. Hoje isso também mudou, todos os cidadãos têm direitos, seja negro, branco, mas também tem deveres, os negros hoje são bem tratados, além de ainda existir pessoas racistas, todos devem cumprir e exigir seus direitos.

o Brasil já mudou muito de lá para cá, apesar de ainda haver muitas injustiças em nosso país, muitos políticos corruptos. Há muita coisa que o Brasil precisa mudar. (Rita, 14 anos)

Nas produções de jovens brasileiros surgem também algumas narrativas a que se tinha convencionado chamar 'narrativas emergentes', por mostrarem consistência lógica e validade global mas tratarem apenas de alguma 'fatia' do período da História solicitado na tarefa. Estas narrativas centram-se em marcadores de um ou outro período e, quase de seguida, em comentários sobre o presente:

No começo do século o clima político não estava bom, o Federalismo fortaleceu o poder das oligarquias porque atendiam o desejo dos cafeicultores 
paulistas, que apoiavam a queda da monarquia... O Brasil não teve grandes progressos por causa da corrupção politica.

Mas o Brasil também é um lugar bom com lugares maravilhosos e até bastante avançado, não tem tanta tecnologia, mas tem. O Brasil é um bom país, também já houve coisas boas nele como a queda do regime militar, e o Brasil também vem crescendo a cada ano. (Jéssica, 14 anos)

Em relação ao Mundo, as narrativas de jovens brasileiros apresentam uma estrutura formal semelhante às nacionais. Sugerem uma mensagem nuclear em que se reconhece a existência de guerras, terrorismo e desigualdades entre países, mas também alguma interligação do país com o mundo, bem como o avanço tecnológico e científico, a evolução de costumes e as preocupações ecológicas.

Dados mais recentes recolhidos em São Paulo (RIBEIRO, 2011) e em Goiânia (SADDI \& SILVA, 2011), e analisados em colaboração com os mesmos investigadores, revelam que a estrutura narrativa se mantém dentro das categorias estabelecidas anteriormente. Embora a tarefa divirja ligeiramente da proposta inicial do Projeto HICON I - centra-se sobre a "história do país" mas numa temporalidade mais abrangente - a maior parte das narrativas nacionais mantém formatos ou comparativo ou emergente. Entre as narrativas emergentes, em que apenas algumas fatias do passado são exploradas, conta-se a do João, de 15 anos:

Em 1500 o Brasil foi descoberto que antes era dominado por índios que hoje em dia é a grande minoria mais todos os Brasileiros tem rastros indígenas no sangue.

Mais a independência do Brasil é um dos fatos históricos mais importantes de nosso país, pois marca o fim do domínio português e a conquista da autonomia política. Muita tentativas anteriores ocorreram e muitas pessoas morreram na luta por este ideal, Tiradentes foi executado pela coroa portuguesa por defender a liberdade de nosso país durante o processo da inconfidência mineira. Em 09 de janeiro de 1822, D. Pedro I recebeu uma carta da corte de Lisboa exigindo seu retorno para Portugal. Há tempos os portugueses insistiam nesta idéia pois pretendiam colonizar o Brasil e a presença de D. Pedro respondeu negativamente os chamados de Portugal e proclamou "Se é para o bem de todos e felicidade geral da nação, digo ao povo que fico". 
Origens, colonização e independência são os marcadores históricos significativos que marcam a identidade nacional deste e doutros jovens brasileiros pesquisados recentemente, mostrando uma perspectiva de progresso sobretudo no plano de valores em torno da liberdade.

\section{Sentidos de Mudança}

Em Portugal, as ideias sobre mudança histórica implícitas nas narrativas juvenis variam de direção, conforme se trate de narrativas nacionais ou mundiais, ou de narrativas nacionais até 2008 ou a partir de 2009. Se até 2008 os jovens viam o seu país com confiança, numa perspectiva de progresso quase linear (pelo menos sobre a fase histórica a partir do derrube da ditadura), nas produções mais recentes - sobretudo de 2010 e 2011 - o reconhecimento da crise torna-se mais nítido. A história nacional já não é uma saga de triunfo sobre condições adversas; contém agora um sentido menos positivo, revelandose tacitamente num movimento pendular de progresso-crise-progresso-crise. Contudo - e este dado é relevante porque mostra conceitos de mudança relativamente complexos - cada fase manifesta-se com características e dimensões específicas, não se podendo ver aí um sentido estereotipado de ciclo fechado, ou de mera repetição da História.

Como exemplo das narrativas até 2008, veja-se a da Joana, considerada narrativa emergente por centrar-se apenas num ou dois segmentos temporais do período de cem anos proposto:

Eu diria que a História de Portugal sofreu muitas mudanças sobretudo no 25 de Abril quando o país se tornou independente, isto é, um país democrático, em 1978 [1974]. Desde então tudo foi diferente, as mulheres foram autorizadas a votar para o governo, os Portugueses puderam expressar a sua opinião enquanto antes do 25 de Abril as pessoas não eram autorizadas a falar sobre o governo e aqueles que se atrevessem a fazê-lo, vinha a polícia política e prendia-os, por vezes matava-os. Não havia liberdade de expressão, nós Portugueses tínhamos que fazer o que eles ordenassem, mas tudo isso mudou, houve uma revolução, houve o 25 de Abril, desde então podemos falar sobre qualquer assunto que nos apeteça. E agora aqui estamos nós, os Portugueses. 
Esta narrativa é paradigmática da crença no progresso do país que os jovens manifestavam anteriormente. Em 2010 e 2011, os jovens reconhecem uma nova fase, de "enorme crise económica que se alastra por todo Portugal".

Quanto a sentidos de mudança nas narrativas brasileiras, nestas há desde o início uma ideia de desenvolvimento e progresso mais equilibrado e complexo em relação ao país e ao mundo do que nas narrativas portuguesas, ao mostrar, e por vezes questionar e problematizar, aspetos negativos em relação ao seu país, a "corrupção”, como dizem vários. Discutem também as relações do Brasil com outros povos, algo que não está tão presente nas narrativas portuguesas (apenas alusões breves à União Europeia). A colonização do Brasil é encarada por alguns de forma muito crítica, como mostra a Mari, de 15 anos, de São Paulo, "acredito que Portugal lucrou muito com a exploração dos bens do Brasil conseqüentemente o Brasil não pode se desenvolver em relação a bens, pois esses deviam ser destinados a Portugal". Mas nem sempre a colonização é encarada com uma atitude de mero criticismo; é o caso de Marco, 16 anos, também de São Paulo, que reconhece que uma consequência dessa colonização "é um tipo de ligação entre os dois países, a lingua, a bistória tem uma ligação muito grande principalmente para o Brasil. Costumes, linguagem, eles ajudaram a escrever nossa bistória".

Este excerto da narrativa do Marco indicia a emergência duma consciência que M. Auxiliadora Schmidt (2011) designa como "criticogenética”, na reflexão dialógica que apresenta sobre as teorias de Paulo Freire e Jörn Rüsen.

\section{O sujeito na História}

Nos dados fornecidos pelos jovens portugueses e brasileiros, explorouse também o lugar do sujeito na História sob duas perspectivas: o eventual protagonismo de grupos ou de indivíduos (heróis, vilões e outros de sentido neutro), e o papel interventivo na História que cada jovem toma para si, ou não. Numa análise transversal e aberta, vê-se que são raros os indivíduos que aparecem nas 'histórias' dos jovens, sobretudo nas dos portugueses (embora nestas entre quase sempre um vilão no país - Salazar). No plano da intervenção pessoal, nas produções até 2008 encontrou-se uma diferença substancial entre a atitude passiva, de espectador da História, do jovem 
português, e a atitude pró-ativa de intervenção crítica, por parte do jovem brasileiro $^{5}$. De realçar, porém, que no caso das produções portuguesas mais recentes (sobretudo em 2011), a atitude interventiva do aluno enquanto sujeito da História emerge já com frequência, face a uma crise que ele começa a sentir na pele. O jovem português vai deixando a sua postura de espectador da História, confortável herdeiro de conquistas politicosociais no passado (como no caso da Joana, na narrativa atrás transcrita). Entre vários testemunhos que exprimem preocupação pelo presente e futuro próximo, há alguns que apontam algum caminho, como o do Jorge, através da sua narrativa vagamente temporalizada:

O meu país, Portugal, nestes últimos 100 anos tem evoluído a nível de tecnologia e estilo de vida, somos um país médio pois há países piores do que o meu como também há países mais evoluídos. O meu país também está em crise, já estivemos pior, é um facto, mas eu com os meus 15 anos nunca vi uma crise, ou seja, isto para mim está mau e é uma novidade pois agora tenho que me privar de muitas coisas, é uma coisa que eu odeio. Esta crise deu-se ao facto de o povo português não tomar uma atitude, o povo português é daqueles que "ah, está mal? Deixo andar". Mas também ao facto de termos políticos [...], o povo está a dormir e vai ter que acordar o mais rápido possível.

Este jovem, em maio de 2011, avisa que o povo "vai ter que acordar o mais rápido possível". Por coincidência (ou não), em manifestações culturais ou cívicas de protesto popular perante as violentas medidas de austeridade impostas ao país por certos poderes, é a canção "Acordai" de Fernando Lopes Graça (1906-1994) que mais se ouve em coro, ao longo de 2012. Quando a opinião pública parecia ainda paralisada perante o avolumar das dificuldades do país, alguns jovens, afinal, indiciavam já uma vontade de intervenção enquanto sujeitos que querem participar na construção da História, no sentido humanista de que fala o filósofo Rüsen. Este sentido humano constitui um dos fundamentos essenciais da consciência histórica, a não perder de vista no

5 Uma nova recolha de dados no Paraná, no âmbito de um estudo conduzido por M. A. Schmidt (UFPR), poderá trazer nova luz a esta questão. 
nosso tempo de incertezas. Algumas vozes juvenis talvez nos ajudem nesse tipo de orientação temporal para o futuro.

\section{O perfil docente: do professor ator ao professor investigador}

De realçar que a investigação em Educação histórica não deverá ser apenas praticada a um nível científico e 'meta-científico' por quem tem estatuto de investigadores experientes. Para que as pistas apontadas pelos resultados não permaneçam como meras prescrições de quem não conhece o terreno, é necessário que os métodos e princípios essenciais destas pesquisas sejam progressivamente apropriados pelos professores que acorrem à formação em Educação histórica, seja inicial, contínua ou pós graduada a nível de mestrado, doutoramento ou pós doutoramento (BARCA, 2007b; CAINELLI \& LOURENÇATO, 2011; SCHMIDT, 2009).

Uma das apostas formativas é a da construção gradual do perfil de "professor investigador social", isto é, do docente que procura compreender a progressão conceptual dos seus alunos com lentes próprias da natureza da História e não apenas em termos de correção e quantidade de conteúdos. Um modelo de formação do "professor investigador social" na área de Educação histórica em Portugal integra preocupações várias (BARCA, 2004), nomeadamente com:

- O perfil do aluno como co-investigador;

- A conceção e implementação da 'aula oficina' construtivista;

- A monitorização das aprendizagens, desde o diagnóstico à metacognição, estabelecendo-se assim uma relação visível entre os níveis de progressão conceptual encontrados e as metas das aprendizagens a avaliar sumativamente;

- A conquista da auto-estima do aluno e do professor.

O modelo de formação aqui sugerido, e que tem dado frutos positivos para aqueles que o abraçam na aula de História, envolve várias fases, sendo cada uma delas composta por um conjunto de tarefas, algumas relativamente complexas. Nos cursos de iniciação a este perfil, costuma ser proposto aos professores: 
1. A recolha inicial de dados sobre as ideias prévias dos alunos acerca de um conceito substantivo, selecionado dentro de uma determinada unidade em estudo numa das suas turmas .

2. A análise das ideias prévias dos alunos segundo um modelo (simplificado) de progressão conceptual: categorização das ideias de alunos desde ideias incoerentes e alternativas até às relativamente válidas.

3. O desenho, planeamento e implementação de uma unidade temática em ambiente de "aula oficina", tendo em conta um refinamento progressivo das ideias históricas dos alunos que foram previamente diagnosticadas.

4. A recolha de dados sobre as ideias dos alunos a posteriori, aplicando o mesmo instrumento do momento inicial.

5. A análise comparativa das ideias dos alunos nos momentos inicial e final da intervenção.

6. A aplicação de um instrumento de metacognição aos alunos e análise das respostas como mais um elemento de monitorização do processo de ensino e aprendizagem.

No seu conjunto, o modelo de formação docente aqui enunciado tem como objetivo central envolver os formandos/professores na aplicação da teoria à prática, proporcionando-lhes âncoras na autoconstrução do perfil de professor-investigador social. Não se advoga um modelo de não diretividade com autonomia total para os formandos ou alunos, que corre o risco de reproduzir práticas e ideias convencionais. A orientação docente, o apoio de outras fontes e a troca de experiências e ideias entre pares são fundamentais para a mudança conceptual positiva do profissional e investigador. Esse perfil de profissionalidade avançada requer um refinamento das competências de análise de dados teoricamente guiada pela reflexão epistemológica sobre a História. As categorias de análise, numa linha de progressão de ideias em História, poderão (deverão) refletir-se depois, de forma aproximada, na avaliação convencional dos resultados de aprendizagem dos alunos - se esta aprendizagem for orientada para a qualidade do pensamento histórico, envolvendo interpretação de fontes e problematização de relações entre passado, presente e horizontes de futuro. Resta acrescentar que, em Portugal como no Brasil, tem havido alguns resultados positivos, concretos, com esta praxis. Para esta 
mudança conceptual, à semelhança do que aconteceu no Reino Unido (incluindo a Irlanda do Norte), em Portugal muito têm contribuído novas abordagens em manuais e nos exames nacionais de História. Mas esta mudança não está ainda alargada, e também não se pretende um percurso de sentido único - os desafios que se colocam no presente passam por tentar reforçar a comunidade de Educação histórica e partilhar vias diversificadas mas válidas que sejam consistentes e eficazes na promoção de uma consciência histórica orientada para o desenvolvimento humano.

\section{Referências}

ARENDS, R. Aprender a ensinar. Lisboa: Mc Graw Hill de Portugal, 1997.

ASHBY, Rosalyn; LEE, Peter; SHEMILT, Denis. Putting Principles into Practice: Teaching and Planning. In: DONOVAN, M. Susanne; BRANSFORD, John (Eds.), How students learn: history in the classroom. Washington: National Academies Press, 2005, p. 79-178.

BARCA, Isabel. O Pensamento Histórico dos Jovens. Braga: CEEP, Universidade do Minho, 2000.

BARCA, Isabel. Aula oficina: do projecto à avaliação. In BARCA, Isabel (Org.), Para uma Educação Histórica de Qualidade. Braga: CIEd, Universidade do Minho, 2004, p. 131-144.

BARCA, Isabel. Marcos de consciência histórica de jovens portugueses. Currículo sem Fronteiras, v.7, n.1, p.115-126, 2007a. Disponível em: http://www.curriculosemfronteiras.org/vol7iss1articles/barca.htm. Acesso em 16 abril 2012.

BARCA, Isabel. Investigação em educação Histórica: fundamentos, percursos e perspectivas. In OLIVEIRA, Margarida, CAINELLI, Marlene; OLIVEIRA, A. F. (Orgs.), Ensino de História: Múltiplos Ensinos em Múltiplos Espaços. Natal RN: Universidade Federal do Rio Grande do Norte, 2007b, p. 23-32.

CAINELLI, Marlene; LOURENÇATO, Lidiane. O ensino da História na transição da quarta para quinta série. Um estudo com a metodologia da educação histórica. In: BARCA, Isabel (Org.), Educação e Consciência Histórica na Era da Globalização. Braga: Universidade do Minho/ Associação de Professores de História, 2011, p. 311-326.

CARDOSO, Ronaldo. Aprender História com Sentido para a Vida - consciência histórica em estudantes brasileiros e portugueses. Tese de doutorado apresentada à Universidade de São Paulo, Brasil, 2011.

CARVAlHO, Manuela. A Competência de interpretação de fontes em História, em países da Europa: um estudo com alunos portugueses, islandeses e italianos no final da escolaridade básica. Dissertação de Mestrado apresentada à Universidade do Minho, 2010.

COMPAGNONI, Alamir, FERnANDES, L., NETTE, A., THEOBALD, Henrique \& SCHMIDT, M. Auxiliadora (2006). Perspectivas da Consciência Histórica em Jovens Brasileiros. In: Anais do VII Encontro Nacional de Pesquisadores em Ensino da História - ENPEH Belo Horizonte, MG: Universidade Federal de Minas Gerais, p. 1-13, 2006. 
COOPER, Hilary; CHAPMAN, Arthur. Constructing history 11-19. Londres: Sage, 2009.

DIAS, Paula (2007). As explicações de alunos sobre o Conflito Israelo-Árabe: um estudo no $3^{\circ}$ ciclo do Ensino Básico. Currículo Sem Fronteiras, 7 (1), 86-114. Currículo sem Fronteiras, v. 7, n. 1, p. 86-114, 2007. Disponível em:

http://www.curriculosemfronteiras.org/vol7iss1articles/dias.htm. Acesso em 16 abril 2012.

FERNANDES, Cármen. A Explicação Histórica com Base em Artefactos Museológicos. Um Estudo com Alunos do $7^{\circ}$ Ano de Escolaridade. Dissertação de Mestrado apresentada à Universidade do Minho, 2009.

FOSNOT, Catherine, Construtivismo e Educação. Lisboa: Edições Piaget, 1999.

FRONZA, Marcelo. Os jovens e as ideias de objetividade e verdade na aprendizagem histórica sobre o passado a partir das histórias em quadrinhos. In: BARCA, Isabel (Org.), Educação $e$ Consciência Histórica na Era da Globalização. Braga: Universidade do Minho/Associação de Professores de História, 2011, p. 179-200.

FULBROOK, Mary. Historical Theory. Londres: Routledge, 2002.

GAGO, Marília. Sentido de tempo ou tempo com sentido(s) - ideias de alunos acerca de identidade e orientação temporal. In: BARCA, Isabel (Org.), Educação e Consciência Histórica na Era da Globalização. Braga: Universidade do Minho/Associação de Professores de História, 2011, p. 53-63.

GEVAERD, Rosi. A ideia de escravidão: da narrativa do manual didático às narrativas produzidas pelos alunos. In: BARCA, Isabel (Org.), Educação e Consciência Histórica na Era da Globalização. Braga: Universidade do Minho/Associação de Professores de História, 2011, p. 159-177.

MARTIN, Raymond. Progress in historical studies. In Fay, B.; Pomper, R.; Vann, R. (Eds.), History and Theory: Contemporary Readings. Malden, MA: Blackwell Press, 1998, p. 377-403.

PINTO, Helena. Evidências patrimoniais para a educação histórica: uma experiência educativa no centro histórico de Guimarães. Currículo sem Fronteiras, v.7, n.1, p.171-185, 2007. Disponível em: http://www.curriculosemfronteiras.org/vol7iss1articles/pinto.htm. Acesso em: 16 abril 2012. PROJECTO “Consciência Histórica - Teoria e Práticas [HICON], (2003-2007). Fundação para a Ciência e Tecnologia. Disponível em:

http://www.fct.pt/apoios/projectos/consulta/vglobal_projecto?idProjecto=49106\&sapiens=2002. Acesso em: 16 abril 2012.

PROJECTO “Consciência Histórica - Teoria e Práticas II” [HICON II], (2007-2011). Fundação para a Ciência e Tecnologia. Disponível em: http://webs.ie.uminho.pt/conscienciahistorica. Acesso em: 16 abril 2012.

RIBEIRO, Regina. Análise de dados de narrativas de jovens em São Paulo. Texto para publicação, 2011. RÜSEN, Jörn. The development of narrative competence in historical learning: an ontogenetic hypothesis concerning moral consciousness. In DUVENAGE, Peter (Ed.), Studies in metabistory. Pretoria: Human Sciences Research Council, 1993, p. 63-84.

RÜSEN, Jörn. Razão histórica. Teoria da História: os fundamentos da ciência histórica. Brasília: Editora UniB, 2001.

SADDI, Rafael; SILVA, Conceição. Análise de dados de narrativas de jovens na cidade de Goiânia. Texto para publicação, 2011. 


\section{Educação Histórica e História da Educação}

SCHMIDT, M. Auxiliadora. Perspectivas da consciência histórica e da aprendizagem em narrativas de jovens brasileiros. Revista Tempos Históricos. Cascavel (PR): Editora Unioeste, v.12, n.1, ano $\mathrm{X}, 2008$, p.81-96.

SCHMIDT, M. Auxiliadora. Investigando para ensinar História: contribuições de uma pesquisa em colaboração. In: BARCA, Isabel; SCHMIDT, M. Auxiliadora (Orgs.), Educação Histórica: Investigação em Portugal e no Brasil. Atas das V Jornadas Internacionais de Educação Histórica. Braga: CIEd, Universidade do Minho, 2009, p. 29-43.

SCHMIDT, M. Auxiliadora. A cultura como referência para investigação sobre consciência histórica: diálogos entre Paulo Freire e Jörn Rüsen. In: BARCA, Isabel (Org.), Educação e Consciência Histórica na Era da Globalização. Braga: Universidade do Minho/Associação de Professores de História, 2011, p. 29-40.

SCHMIDT, M. Auxiliadora; BARCA, Isabel; MARTINS, Estêvão Rezende (Orgs.), Jörn Rüsen e o ensino de História. Curitiba-PR: Editora UFPR, 2010.

SIMÃO, Ana Catarina. A construção da evidência histórica: concepções de alunos do 3.0 ciclo do ensino básico e secundário. Tese de doutoramento apresentada à Universidade do Minho, 2007.

TORGAL, Luís Reis. Ensino da História: o despertar para um campo de investigação. In: TORGAL, LUÍS REIS, MENDES, J. AMADO \& CATROGA, FERNANDO (Eds.), História da História em Portugal. Lisboa: Círculo de Leitores, 1996, p. 431-489. 